\title{
High-resolution continuous-flow analysis setup for water isotopic measurement from ice cores using laser spectroscopy
}

\author{
B. D. Emanuelsson ${ }^{1,2}$, W. T. Baisden ${ }^{2}$, N. A. N. Bertler ${ }^{1,2}$, E. D. Keller ${ }^{2}$, and V. Gkinis ${ }^{3}$ \\ ${ }^{1}$ Antarctic Research Centre, Victoria University of Wellington, PO Box 600, Wellington 6140, New Zealand \\ ${ }^{2}$ National Isotope Centre, GNS Science, 30 Gracefield Road, Lower Hutt 5010, New Zealand \\ ${ }^{3}$ Centre for Ice and Climate, Niels Bohr Institute, University of Copenhagen, Juliane Maries Vej 30, \\ 2100 Copenhagen, Denmark
}

Correspondence to: B. D. Emanuelsson (daniel.emanuelsson@ vuw.ac.nz)

Received: 19 September 2014 - Published in Atmos. Meas. Tech. Discuss.: 02 December 2014

Revised: 28 April 2015 - Accepted: 06 July 2015 - Published: 17 July 2015

Abstract. Here we present an experimental setup for water stable isotope $\left(\delta^{18} \mathrm{O}\right.$ and $\left.\delta \mathrm{D}\right)$ continuous-flow measurements and provide metrics defining the performance of the setup during a major ice core measurement campaign (Roosevelt Island Climate Evolution; RICE). We also use the metrics to compare alternate systems. Our setup is the first continuousflow laser spectroscopy system that is using off-axis integrated cavity output spectroscopy (OA-ICOS; analyzer manufactured by Los Gatos Research, LGR) in combination with an evaporation unit to continuously analyze water samples from an ice core.

A Water Vapor Isotope Standard Source (WVISS) calibration unit, manufactured by LGR, was modified to (1) enable measurements on several water standards, (2) increase the temporal resolution by reducing the response time and (3) reduce the influence from memory effects. While this setup was designed for the continuous-flow analysis (CFA) of ice cores, it can also continuously analyze other liquid or vapor sources.

The custom setups provide a shorter response time $(\sim 54$ and $18 \mathrm{~s}$ for 2013 and 2014 setup, respectively) compared to the original WVISS unit ( $\sim 62 \mathrm{~s})$, which is an improvement in measurement resolution. Another improvement compared to the original WVISS is that the custom setups have a reduced memory effect.

Stability tests comparing the custom and WVISS setups were performed and Allan deviations $\left(\sigma_{\text {Allan }}\right)$ were calculated to determine precision at different averaging times. For the custom 2013 setup the precision after integration times of $10^{3} \mathrm{~s}$ is 0.060 and $0.070 \%$ ofor $\delta^{18} \mathrm{O}$ and $\delta \mathrm{D}$, respectively. The corresponding $\sigma_{\text {Allan }}$ values for the custom 2014 setup are $0.030,0.060$ and $0.043 \%$ for $\delta^{18} \mathrm{O}, \delta \mathrm{D}$ and $\delta^{17} \mathrm{O}$, respectively. For the WVISS setup the precision is $0.035,0.070$ and $0.042 \%$ after $10^{3} \mathrm{~s}$ for $\delta^{18} \mathrm{O}, \delta \mathrm{D}$ and $\delta^{17} \mathrm{O}$, respectively. Both the custom setups and WVISS setup are influenced by instrumental drift with $\delta^{18} \mathrm{O}$ being more drift sensitive than $\delta \mathrm{D}$. The $\sigma_{\text {Allan }}$ values for $\delta^{18} \mathrm{O}$ are 0.30 and $0.18 \%$ for the custom 2013 and WVISS setup, respectively, after averaging times of $10^{4} \mathrm{~s}(2.78 \mathrm{~h})$. Using response time tests and stability tests, we show that the custom setups are more responsive (shorter response time), whereas the University of Copenhagen (UC) setup is more stable. More broadly, comparisons of different setups address the challenge of integrating vaporizer/spectrometer isotope measurement systems into a CFA campaign with many other analytical instruments.

\section{Introduction}

Ice cores are valuable archives from which we can gain knowledge of past atmospheric processes and climate by investigating records that are preserved in the ice or in entrapped gas bubbles, e.g., from water molecules, chemical impurities, particulates and methane gas (e.g., Petit et al., 1999; EPICA Community Members, 2004; WAIS Divide Project Members, 2013). Water stable isotopes $\left(\delta^{18} \mathrm{O}\right.$ and 
$\delta \mathrm{D}$, hereafter referred to as $\delta$ ) preserved in ice are among the most powerful proxy records of past climate and atmospheric processes, which greatly extend limited instrumental and observational records from Antarctica that are available only over the last century (e.g., Steig et al., 2013; Thomas et al., 2013).

$\delta$ records in ice cores have most frequently been used as a site temperature proxy (Epstein and Mayeda, 1953; Dansgaard, 1964), but sea ice extent, atmospheric circulation, transportation pathways, changes in source region as well as post-depositional effects (wind scour, diffusion, etc.) also influence the $\delta$ signal (Jouzel et al., 1997; Masson-Delmotte et al., 2008; Küttel et al., 2012; Sinclair et al., 2013). Deuterium excess (d-excess) is a second-order proxy (d-excess $=\delta \mathrm{D}-8 \times \delta^{18} \mathrm{O}$; Craig, 1963; Dansgaard, 1964) commonly interpreted as describing relative humidity and temperature at the moisture source region, as a result of the kinetic isotope effect during evaporation (Merlivat and Jouzel, 1979).

Laser spectrometry has made continuous-flow analysis (CFA) of $\delta$ in ice core melt streams possible (Gkinis et al., 2010; Maselli et al., 2013), replacing measurement of discrete samples (e.g., Rhodes et al., 2012; Sinclair et al., 2013). Following the first measurements of $\delta$ from laser absorption spectrometry (Kerstel et al., 1999), improvements in commercially available analyzers (Baer et al., 2002; Crosson, 2008; Berman et al., 2013; Steig et al., 2014) have made them increasingly suitable to analyze water vapor continuously. High temporal resolution measurement applications have included atmospheric sciences (e.g., Johnson et al., 2011; Aemisegger et al., 2012; Steen-Larsen et al., 2013), ice core records (Gkinis et al., 2010; Steig et al., 2013; Maselli et al., 2013), ecology (e.g., Lee et al., 2007) and hydrology (e.g., Goebel and Lascano, 2012).

Successful measurement of a liquid water stream using laser spectrometry requires that the liquid sample stream is converted to vapor and compared to water standards of known isotopic composition to achieve calibration. Reliable calibration vaporizing units have been developed for research (Gkinis et al., 2010; Schmidt et al., 2010; Sturm and Knohl, 2010; Steig et al., 2014), and calibration units are available commercially: the Water Vapor Isotope Standard Source (WVISS) manufactured by Los Gatos Research (LGR) and Standards Delivery Module (SDM) by Picarro. The WVISS system vaporizes one standard using a self-aspirating nebulizer into a heated $\left(75^{\circ} \mathrm{C}\right)$ evaporation jar, whereas the SDM uses a syringe-pump-based system that can switch between two standards. For $\delta$ CFA of ice cores, a range of criteria including the stability and response time of the vaporizer/spectrometer system must be understood and matched to practical requirements, including the operation of other CFA analyzers and the collection of discrete samples.

Here, we present new experimental setups and identify the following aims for the characterization of new and previously reported systems: (1) enable accurate calibration to several water standards, (2) increase the temporal resolution by reducing the response time and (3) reduce memory effects. With regard to the first aim, calibration to two standards allows us to properly normalize our results on the VSMOW/SLAP scale (Gonfiantini, 1978; Coplen, 1996). In addition, we are able to characterize the instrumental response time using the step changes between standards. We define the response time as the time from the first 5 to the last $5 \%$ of the response to a step change in $\delta$. A short response time is desirable to minimize the time required for completing calibration cycles and to maximize the resolution with which the $\delta$ signal that is preserved in the ice is captured. Alongside the response time, we define a memory effect as causing an asymmetric tail in the last $5 \%$ of the step in $\delta$ values, with an extended tail compared to our empirical fit. Avoiding memory effects is desirable given the large range of $\delta$ in ice cores and in the standards required for normalization.

A key challenge we address is the integration of vaporizer/spectrometer isotope measurement systems into a CFA campaign with many other instruments. In the case of a multi-instrument CFA campaign, the competing demands of different instrumentation and associated logistics of extended continuous operation may require the CFA isotope measurement system to be constructed so that the entire multiinstrument CFA system can be optimized. For example, CFA methane measurements require long uninterrupted periods of melting due to large memory effects, whereas $\delta$ measurements for the custom and WVISS setups will benefit from more frequent calibration. Therefore, the number of consecutive core sections that are stacked on top of one another and melted continuously without interruption for calibration can necessitate a compromise between the ideal time intervals of continuous melting for each analysis type.

Here, we describe the design and performance characterization of two custom vaporizer/spectrometer $\delta$ CFA employed for analysis of an ice core - the Roosevelt Island Climate Evolution (RICE) Antarctic ice core, retrieved from $79^{\circ} 21^{\prime} 46^{\prime \prime} \mathrm{S}, 161^{\circ} 42^{\prime} 3^{\prime \prime} \mathrm{W}$ (560 m a.s.l.) on an ice rise (Conway et al., 1999) situated at the northeastern edge of the Ross Ice Shelf. The $\delta$-CFA systems were required to yield maximum response resolutions for relating ice core $\delta$ to sea ice extent, atmospheric circulation modes and local temperature using reanalysis data (1979 to 2012) and in response to past climate events while maintaining stable and accurate $\delta$ CFA throughout the analyzed depths of the $763 \mathrm{~m}$ ice core. Our $\delta$ CFA setups are compared in response times and stability to a similar $\delta$-CFA ice core setup, the University of Copenhagen (UC) setup and the commercially available WVISS (Table 1). This is the first study within the field of ice core science that provides a detailed characterization and comparison between $\delta$-CFA setups that are using the new generation of offaxis integrated cavity output spectroscopy (OA-ICOS) and cavity ring-down spectroscopy (CRDS) spectroscopy techniques. The performance of the $\delta$-CFA systems is described and evaluated in the context of the RICE project, with a fo- 
cus on the characterization to aid the selection and potential customization of $\delta$-CFA systems for future CFA campaigns.

\section{Experimental}

Results are reported in $\delta$ notation, representing the abundance of rare isotopes as a deviation from a reference ratio: $\delta=R / R_{\text {SMOW }}-1$, where $R$ and $R_{\text {SMOW }}$ are the ratio between rare and abundant isotopes ${ }^{18} \mathrm{O} /{ }^{16} \mathrm{O}$, or $D / H$ in the sample and in VSMOW (Vienna Standard Mean Ocean Water), respectively. Results are reported in per mil, \%o.

\subsection{Isotope water analyzer (IWA-35EP)/triple isotope water analyzer (TIWA-45EP) laser spectroscopy system}

In this study, we use an absorption spectroscopy instrument based on OA-ICOS technology in combination with an evaporation unit to continuously analyze sample from an ice core or water standards during calibration. The absorption spectroscopy instrument is an IWA manufactured by LGR.

The main system we describe (custom 2013) was developed and employed for the RICE CFA melting campaign (0 to $500 \mathrm{~m}$ ) in 2013. It consists of a commercially available IWA from LGR and a customized furnace and evaporation chamber, which was built and fitted inside a modified WVISS calibration unit. In addition to its function as a calibration unit, the custom 2013 setup (Table 1) was used as a sample introduction system, in which the ice core melt stream is continuously vaporized and introduced to the IWA. A similar system (custom 2014) incorporating improvements was assembled for the 2014 RICE CFA melting campaign (500 to $761 \mathrm{~m}$ ) and is described briefly.

The IWA-35EP analyzer uses a near-infrared, tunable diode laser that scans over three nearby absorption peaks, $\mathrm{H}_{2}^{16} \mathrm{O}, \mathrm{H}_{2}^{18} \mathrm{O}$ and $\mathrm{HDO}$, located near the $1.4 \mu \mathrm{m}$ wavelength. The instrument uses an OA-ICOS technique (Baer et al., 2002), in which the laser is directed off axis into an optical cavity. The semi-transparent cavity absorption cell has highly reflective mirrors, yielding an effective path length of several kilometers. The transmitted intensities are recorded by a photo detector. Laser spectroscopy analyzers are able to provide simultaneous measurements of $\delta^{18} \mathrm{O}, \delta \mathrm{D}$ and water vapor mixing ratios.

Aemisegger et al. (2012) characterized the response time characteristics of commercially available analyzers, finding that the L1115-i Picarro CRDS analyzer has a longer response time compared to the LGR IWA by $\sim 31$ and $22 \mathrm{~s}$ for $\delta \mathrm{D}$ and $\delta^{18} \mathrm{O}$, respectively. Additionally, the signal for the L1115-i is biased by isotope-specific time lags (henceforth called lag bias), with $\delta \mathrm{D}$ having a $\sim 10 \mathrm{~s}$ longer response time than $\delta^{18} \mathrm{O}$. A $\delta$ signal without lag bias is important when calculating high-frequency d-excess values. The faster response time and lack of lag bias of our custom se- tups allows us to explore the maximum extent to which the rapidly changing $\delta$ signal preserved in an ice core can be resolved. The pumping rate of the cavity is higher for the IWA (500 to $800 \mathrm{~mL} \mathrm{~min}^{-1}$ ) compared to the L1115-i $\left(25 \mathrm{~mL} \min ^{-1}\right)$ setup, which increases the turnover rate of the cavity, a contributing factor to the short response time of the IWA (Aemisegger et al., 2012).

Sturm and Knohl (2010) reported on temperature sensitivity of the IWA. Recent IWA models have an enhanced performance (EP) feature, which improved the thermal control of the cavity by keeping the temperature of the cavity $\left(\sim 46.3^{\circ} \mathrm{C}\right)$ stable and elevated above the ambient temperature. Recent models also have the capability to measure $\delta^{17} \mathrm{O}$, such as the TIWA-45EP from LGR (Berman et al., 2013) and L2140-i from Picarro (Steig et al., 2014). Our IWA-35EP analyzer was updated in December 2013 to a TIWA-45EP analyzer, which added the capability of measuring $\delta^{17} \mathrm{O}$ using a second tunable diode laser. The update of the analyzer enabled us to include $\delta^{17} \mathrm{O}$ in our evaluation of the WVISS and the 2014 custom setup.

\subsection{Evaporation/vapor introduction systems}

We evaluate the performance of two water evaporation units, the WVISS calibration unit and the custom 2013 setup. In addition to this we present preliminary data and results from the updated custom 2014 setup and new previously unpublished results from a CRDS L2140-i Picarro ice core setup (UC setup) with a custom-made vaporizer (vaporizer and setup described in Gkinis et al., 2010; Steig et al., 2014). The UC setup was optimized with stability in mind.

\subsubsection{WVISS system}

The original WVISS unit (WVISS v.2 evaporation unit; manufactured December 2013) was set up to run a single water standard. A stream of water standard is continuously evaporated by the WVISS during calibration events. The WVISS unit consists of a heated $\left(75^{\circ} \mathrm{C}\right) 1.1 \mathrm{~L}$ jar into which a nebulizer injects a constant stream of minuscule water droplets that rapidly evaporate. For incoming dry air, the WVISS incorporates a built-in compressor and drier, but we chose to plumb to an external compressed dry air source to maximize stability and minimize noise and vibration in the laboratory. The dry air is split up into two flows inside the WVISS: one constant flow that goes through the nebulizer and the second, constituting the majority of the dry air flow, that is regulated by a mass flow controller (MFC) and is introduced to the evaporation jar. Tests of the WVISS unit were performed using external compressed dry air $(<20 \mathrm{ppm})$. When provided by the manufacturer, the nebulizer (Savillex, PFA C-flow 50 nebulizer) is set up to self-aspirate a flow of $50 \mu \mathrm{L} \mathrm{min}{ }^{-1}$ from a $0.5 \mathrm{~L}$ glass water bottle. We use a multi-port valve (C25-3186EMH, VICI), which enables us to use more than one water standard. Additional flow resistance introduced by 
Table 1. Technical detail and properties for the different setups.

\begin{tabular}{llllll}
\hline Setup name & Analyzer & Manufacturer & Technology & Vaporizer & Reference \\
\hline Custom 2013 & IWA-EP35 & LGR & OA-ICOS & modified WVISS & This study \\
Custom 2014 & TIWA-EP45 & LGR & OA-ICOS & modified WVISS & This study \\
WVISS & TIWA-EP45 & LGR & OA-ICOS & WVISS & \\
UC & L2130-i & Picarro & CRDS & Capillary and a furnace, & Gkinis et al. (2010, 2011); \\
& & & see ref. & Steig et al. (2013) \\
\hline
\end{tabular}

the multi-port valve necessitated the use of a peristaltic pump (P2; $\mathrm{MP}^{2}$, Elemental Scientific) to provide a more stable water flow to the evaporation chamber. The WVISS unit is described more in depth in Rambo et al. (2011) and Kurita et al. (2012).

The performance of an unaltered WVISS evaporation unit was also evaluated, using the TIWA-45EP LGR analyzer.

\subsubsection{Experimental setup for water vapor isotope measurements}

Building on the design of the WVISS as a calibration unit supporting measurement of vapor samples, a key principle of our customized design was that both the ice core melt stream and isotopic standards passed through the same vaporization process. All changes to the WVISS involved readily available components that could easily be integrated within the WVISS shell and controlled with the IWA-WVISS system.

In the custom setups, we modified the following aspects of the setup: (1) volume of the evaporation chamber, (2) materials, (3) evaporation temperature, (4) introduction of the sample into the carrier gas and (5) reduction of travel distances of the samples. We will explain the rationale and outcome of these changes in the following sections.

\section{Volume of the evaporation chamber}

We reduced the internal volume of the WVISS evaporation chamber of $1.1 \mathrm{~L}$ to $40 \mathrm{~mL}$ in the 2013 custom vaporizer. The substantially smaller volume increases the turnover rate and reduces the response time. This is particularly important when analyzing multiple standards and/or a rapidly changing continuous flow signal (e.g., from an ice core). The maximum resolution will be determined by the time it takes to replace the vapor volume in the evaporation chamber.

The evaporation chamber volume is less important for onestandard calibration setups (without the requirement of rapid volume exchange), as used for example to obtain real time measurements of atmospheric vapor for which the WVISS was designed (Rambo et al., 2011; Aemisegger et al., 2012).

\section{Material}

The WVISS setup has a Savilex sealed $1.1 \mathrm{~L}$ jar evaporation chamber. For the custom 2013 setup we use borosilicate glass

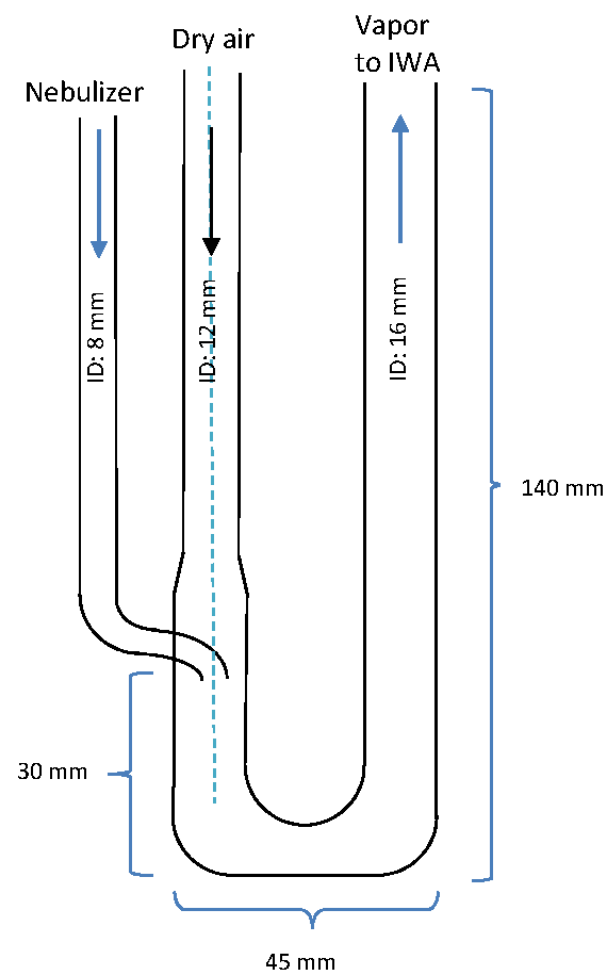

Figure 1. Diagram of glass evaporation chamber. A moist air stream is generated from the nebulizer, merged with the MFC regulated dry air, mixed at $170^{\circ} \mathrm{C}$ and subsequently flows out of the glass evaporation chamber to the IWA.

for the evaporation chamber. A cavity was milled within an aluminum block to hold the glass evaporation chamber in place and to conduct heat from the furnace efficiently into the evaporation chamber. Glass was chosen as the material for the evaporation chamber because it can be molded when heated to form the precise desired shape of the chamber (Fig. 1).

\section{Evaporation temperature}

To achieve complete evaporation at higher vapor throughput rates, we increased the temperature of our custom furnace to $\sim 170^{\circ} \mathrm{C}$ compared to the WVISS, which operates at $75^{\circ} \mathrm{C}$. The temperature of the custom furnace and WVISS evapora- 
tion jar is regulated using a PID regulated Omega temperature controller (CN7500).

\section{Introduction of the sample into the carrier gas}

Filtered compressed dry air $(<20$ ppm) was used for evaporation of water sample flow and to transport the vapor to the IWA. Only a small portion of the total dry air flow goes through the nebulizer. The nebulizer injects a mixture of water and dry air into a glass evaporation chamber inside a customized furnace, where the sample water is instantaneously evaporated.

In the 2013 evaporation chamber, the moist air stream generated by the nebulizer (Fig. 1) and a line with dry air flow passes through the furnace parallel to each other in separate lines. These two gas streams are later merged, with the vapor line from the nebulizer being centered inside the dry air stream at the merger. Separating the two lines has the advantage that it provides a longer residence time in the furnace for the sample that is injected by the nebulizer. This ensures complete evaporation; if all of the dry air were to be introduced directly adjacent to the nebulizer, the throughput rate of moist air could exceed the rate at which the dry air can be heated, causing inefficient and incomplete evaporation at a high vapor throughput rate. The dry air line represents the majority of the total air flow $\left(0\right.$ to $\left.10 \mathrm{~L} \mathrm{~min}^{-1}\right)$ and the dry air flow is controlled by an Omega MFC.

After the vapor has left the furnace the internal pluming of the WVISS was used to transport the sample vapor to the analyzer. The water vapor concentration introduced to the analyzer was $\sim 20000 \mathrm{ppm}$. Excess vapor was vented to the atmosphere through the WVISS exhaust.

Further modifications were made in a custom 2014 setup, which uses two ceramic heating elements $(122 \mathrm{~mm}, 250 \mathrm{~W}$, and $230 \mathrm{~V}$ ) to heat a stainless steel evaporation block to $165^{\circ} \mathrm{C}$. The block is painted with high-temperature black paint to uniformly absorb radiant heat generated by the elements within a reflective cavity. The inner surface of the block is electro-polished. The same nebulizer is used as in the 2013 setup, and the mixing chamber is of similar dimensions. Dry air is pre-warmed in baffles and introduced adjacent to the nebulizer. Compared to the 2013 setup, a higher sample flow of $\sim 150 \mu \mathrm{L} \mathrm{min}{ }^{-1}$ matched with dry air flow to achieve $\sim 20000$ ppm water vapor concentrations is used. Preliminary results from the 2014 setup are reported here and differ only in the vaporizer construction and in delivery of mixed vapor to the IWA directly through an open split. The 2014 open split is a simple step down in PFA tubing sizes rather than within the WVISS plumbing and exhaust system: 1/4" O.D. tubing is connected to the IWA and inserted $5 \mathrm{~cm}$ and centered within the larger size tubing 1/2" O.D. carrying flow from the vaporizer.

\section{Reduction of travel distance of the sample}

The 1/4" PFA tubing between the WVISS and the IWA, which provides the analyzer with sample, was kept short $(59 \mathrm{~cm})$ and a heat tape was wrapped around the tubing to prevent condensation and reduce adsorption to the tubing walls.

The sample flow from the ice core melt head separates the sample stream from the inner and outer parts of the core, allowing for clean chemical sampling from the inner section. For CFA $\delta$ measurements it is not necessary to have an ultra-clean sampling regime, but we recommend taking the sample stream from the inner line to prevent blocking of the nebulizer. The $\delta$-measurement flow requires only 50 to $150 \mu \mathrm{L} \mathrm{min}{ }^{-1}$ and thus represents a minimal draw on the available sample volume. The melt rate was monitored to allow the association of each continuous ice core measurement with a depth.

The old air entrapped in the ice is first separated from the water sample by a debubbler (DB1) and led to spectroscopic analyzers to measure $\mathrm{CH}_{4}$ and $\delta^{18} \mathrm{O}$ in the air. After this step air bubbles are introduced to the keep the water sample flow segmented. To keep the water vapor mixing ratio generated from the evaporation unit constant, the introduced bubbles are removed in DB2 before the evaporation unit and multiport valve (V2). A more detailed description of the melt head and the sealed debubbler (DB1, Fig. 2) used during the 2013 and 2014 RICE melting campaign is provided in Bigler et al. (2011). The multi-port valve (C25-3186EMH, VICI) enables us to switch between samples from the ice core and multiple water standards (V2, Fig. 2 and Table 2). Switching between sample and calibration cycles was initiated through a control and data acquisition interface that was built in LabVIEW software (National Instruments). Once the calibration cycle was initiated, switches between water standards were automated. RS-232-to-USB cables were used to control and $\log$ positions of the valves (stored in calibration log files). P2 provides a constant water flow rate of 50 to $150 \mu \mathrm{L} \mathrm{min}^{-1}$ to the nebulizer (Savillex, PFA C-flow 50 nebulizer, part no. 800-1-005-01-00). PFA tubing was used for the water and vapor flows.

The custom 2013 setup has proven to be reliable. The system performed without malfunction during the entire 2013 RICE melting campaign of 35 processing days.

\section{Results and discussion}

\subsection{Signal stability (instrument drift)}

Stability tests were performed to determine precision for different lengths of averaging times $\left(\tau_{m}\right)$ and to quantify at which timescales instrumental drift affects the $\delta$ signal (Allan, 1966; Werle, 2011). Allan deviation ( $\sigma_{\text {Allan }}$, square root of Allan variance, Eq. (1); Werle, 2011) was calculated us- 
Table 2. $\delta^{18} \mathrm{O}$ and $\delta \mathrm{D}$ discrete-IWA measurements of water standards in relation to the VSMOW/SLAP scale and their role during two-point calibration.

\begin{tabular}{lrrrrrl}
\hline Standard & $\mathrm{N}$ & $\delta^{18} \mathrm{O}(\%)$ & $\pm \sigma$ & $\delta \mathrm{D}(\% o)$ & $\pm \sigma$ & Calibration \\
\hline WS 1 & 4 & -10.84 & 0.099 & -74.15 & 0.938 & QA/QC \\
RICE & 30 & -22.54 & 0.049 & -175.02 & 0.193 & Slope and normalization \\
ITASE & 30 & -37.39 & 0.046 & -299.66 & 0.183 & Slope \\
\hline
\end{tabular}

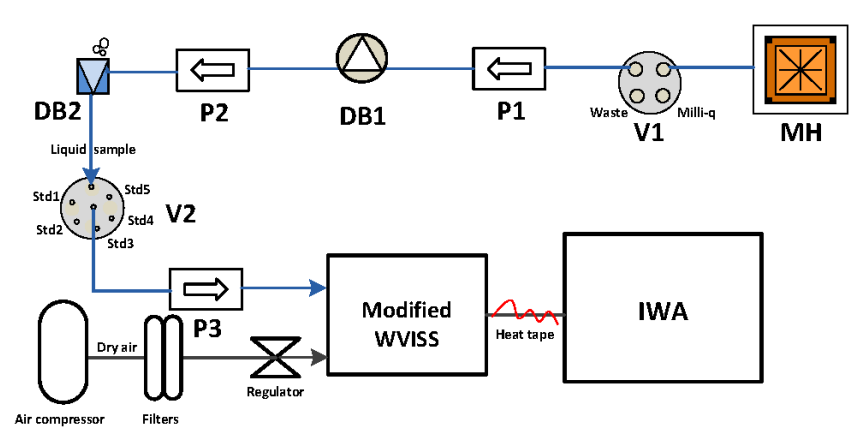

Figure 2. Flow chart of CFA IWA-custom vaporizer setup, where MH stands for melt head, $V$ for valve, $P$ for peristaltic pump and DB for debubbler. Blue lines represent the liquid part of the setup and the black lines represent the dry and moist air portion.

ing several stability tests consisting of measurements on the Lower Hutt Milli-Q water (LHW) standard for extended time periods. Tests were performed on the 2013 and 2014 custom and the WVISS setups at water vapor concentrations of $\sim 20000$ ppm (Table 3).

$\sigma_{\text {Allan }}^{2}\left(\tau_{m}\right)=\frac{1}{2 m} \sum_{j=1}^{m}\left(\bar{\delta}_{j+1}-\bar{\delta}_{j}\right)^{2}$,

where $\tau_{m}$ is the averaging time and $\bar{\delta}_{j+1}$ and $\bar{\delta}_{j}$ are the mean values of neighboring time intervals $j$ and $j+1$.

Representative results from the 29 June 2013 are provided in Fig. 3. For $\delta^{18} \mathrm{O}$ two relatively stable periods can be seen separated by a transition period of instrumental drift between 11 and $13 \mathrm{~h}$. We find that the instrumental drift is nonlinear and therefore challenging to correct for.

\subsubsection{Custom vaporizer}

The Allan deviation analysis for the custom 2013 setup shows that precision increases with longer averaging times until the optimal averaging time is reached after $\sim 200$ and $\sim 600 \mathrm{~s}$ with a precision of $\sim 0.04$ and $\sim 0.07 \%$ o for $\delta^{18} \mathrm{O}$ and $\delta$ D, respectively (Figs. 4 and 5). For longer averaging times, instrumental drift becomes apparent. For this reason, averaging times beyond these values will have poorer precision.

After an averaging time of $60 \mathrm{~s}$ (approximately the response time of the whole ice core CFA setup) a precision of
0.05 and $0.15 \%$ is achieved for $\delta^{18} \mathrm{O}$ and $\delta \mathrm{D}$, respectively. This level of precision is comparable to IRMS analyzes for $\delta^{18} \mathrm{O}$ (IRMS $\delta^{18} \mathrm{O}: 0.024$ to $0.1 \%$ ) and outperforms IRMS analyzes for $\delta$ D (IRMS $\delta$ D: 0.5 to $1.0 \%$; Sturm and Knohl, 2010 , and references therein).

Due to competing requirements of various CFA analytical lines, calibrations were not run frequently enough during the 2013 RICE ice core processing campaign to avoid influence from instrumental drift on the CFA $\delta$ data. Calibrations were on average conducted every $2.4 \mathrm{~h}$. Thus, the maximum temporal distance of any $\delta$-CFA measurement to a calibration event is $\sim 1.2 \mathrm{~h}$. The peak uncertainty is therefore given by the Allan deviation after $1.2 \mathrm{~h}$, which is $\sim 0.17$ and $\sim 0.13 \%$ o for $\delta^{18} \mathrm{O}$ and $\delta \mathrm{D}$, respectively (Figs. 4. and 5). Analytical uncertainty in d-excess was estimated to range between 0.31 and $1.37 \%$ o using Eq. (2). We note that Eq. (2) assumes $\delta^{18} \mathrm{O}$ and $\delta \mathrm{D}$ are uncorrelated, which was verified to be true for the vast majority of our measurements on standards averaged at $15 \mathrm{~s}$ intervals. Peak uncertainty $(1.37 \%$ o $)$ occurs at the center point between calibrations (Figs. 4 and $5 ; 1.2 \mathrm{~h}=4320 \mathrm{~s}$ ) and the minimum uncertainty $(0.31 \%$ o $)$ occurs near calibration points, within the optimal integration time for $\delta^{18} \mathrm{O}(200 \mathrm{~s})$.

$\sigma_{\mathrm{d}}=\left[\left(\sigma_{\delta \mathrm{D}}\right)^{2}+\left(8 \cdot \sigma_{\delta^{18} \mathrm{O}}\right)^{2}\right]^{1 / 2}$

For d-excess ice core measurements, a precision of $\leq 0.1$ and $\leq 1.0 \%$ o for $\delta^{18} \mathrm{O}$ and $\delta \mathrm{D}$, respectively, is required $\left(\sigma_{\mathrm{d}}=1.28 \%\right.$; Masson-Delmotte et al., 2008). The $\delta^{18} \mathrm{O}$ measurements are more drift sensitive compared to $\delta \mathrm{D}$ data and are therefore the limiting factor for d-excess data. To achieve high-precision measurements for $\delta^{18} \mathrm{O}(<0.1 \%)$, a standard would have to be run for drift correction every $\sim 1 \mathrm{~h}$, which is incompatible with CFA methane gas analyses.

To reduce the response time and the influence from instrumental drift, we are currently working towards a new setup, focusing on reducing the response time and the influence from instrumental drift even further. A reduced response time would allow us to run a drift standard during melting, only missing a small quantity of ice core analysis. Such an approach would accommodate competing requirements, such as frequent calibrations for isotope measurements and long periods of uninterrupted melting for methane measurements. Furthermore, if the instrumental drift is reduced then less frequent calibrations will be required. 
Table 3. Date, duration, mean water vapor concentration and standard deviation for stability tests.

\begin{tabular}{llrrr}
\hline Date & Setup & Duration (h) & Mean (ppm) & Std (ppm) \\
\hline 24 May 2013 & Custom 2013 & 18.45 & 21466 & 639 \\
01 June 2013 & Custom 2013 & 23.81 & 19941 & 479 \\
09 June 2013 & Custom 2013 & 22.04 & 19530 & 400 \\
23 June 2013 & Custom 2013 & 23.98 & 19870 & 456 \\
29 June 2013 & Custom 2013 & 23.26 & 19642 & 401 \\
24 January 2014 & WVISS & 31.22 & 18092 & 145 \\
28 January 2014 & WVISS & 24.47 & 19770 & 135 \\
30 January 2014 & WVISS & 31.67 & 19641 & 144 \\
19 July 2014 & Custom 2014 & 30.49 & 20216 & 304 \\
20 July 2014 & Custom 2014 & 18.92 & 21486 & 132 \\
30 May 2014 & Gkinis 2014 & 30.00 & - & - \\
\hline
\end{tabular}
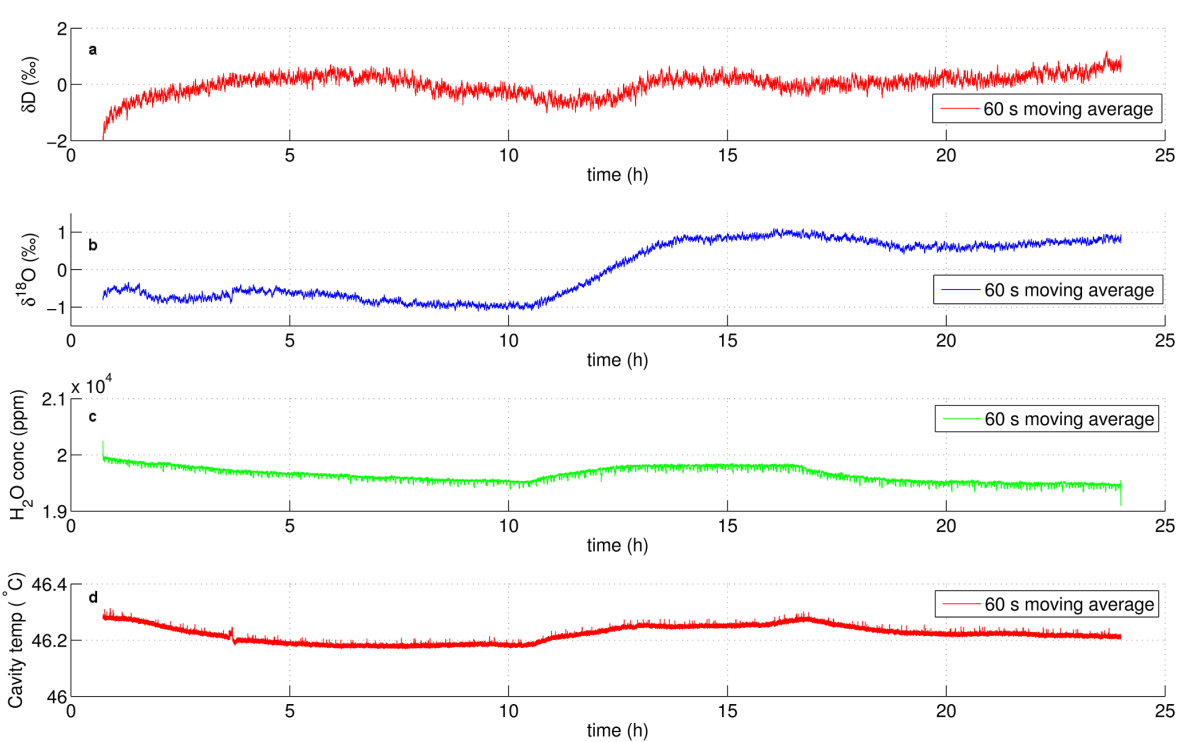

Figure 3. Results from a stability test using the 2013 custom vaporizer setup, measured over a $24 \mathrm{~h}$ period. Moving averages of $60 \mathrm{~s}$ of the $2 \mathrm{~Hz}$ data are displayed. Deviation from mean value is shown for each point in (a) for $\delta \mathrm{D}$ and (b) for $\delta^{18} \mathrm{O}$. (c) Water vapor concentration (ppm) and (d) analyzer cavity temperature $\left({ }^{\circ} \mathrm{C}\right)$.

\subsubsection{WVISS system}

For the WVISS system the optimum averaging times are 700, 1000 and $1500 \mathrm{~s}$ with precisions of $0.04,0.06$ and $0.04 \%$ for $\delta^{18} \mathrm{O}, \delta \mathrm{D}$ and $\delta^{17} \mathrm{O}$, respectively.

The optimal averaging time is reached faster for the custom setups compared to the WVISS system, indicating that the custom setup has higher precision compared to the WVISS during shorter integration times (e.g., 0 to $300 \mathrm{~s}$ for $\delta^{18} \mathrm{O}$, Fig. 4). However, the 2013 custom setup is more susceptible to long-term drift beyond the optimal averaging time (Figs. 4 and 5).

The variability observed at long averaging times (beyond the optimum averaging time) shows the randomness of the drift, as drift occurs after different lengths of times for different tests (Figs. 4, 5 and S1 in the Supplement). Previous studies have shown results from singular tests (Gkinis et al., 2010; Sturm and Knohl, 2010; Aemisegger et al., 2012), averages from several tests (Steig et al., 2014) or from several tests but only for short integration times $(\leq 1000 \mathrm{~s}$; Maselli et al., 2013). Showing results from a suite of tests provides an improved estimate of the uncertainty of the results and the nonlinear nature of the drift. However, if the system is less drift sensitive, a single long-term test can be sufficient to characterize the stability of the system.

Aemisegger et al. (2012) conducted stability test comparisons for averaging times from 0 to $10^{4} \mathrm{~s}(2.78 \mathrm{~h})$. However, to investigate drift for longer averaging times, we consider averaging times up to $10^{5} \mathrm{~s}(27.8 \mathrm{~h})$ and compare these results to the UC setup (Picarro instrument; L2140-i).

Our results show that the custom and WVISS setups are affected by instrumental drift. At averaging times of $10^{4} \mathrm{~s}$ the 


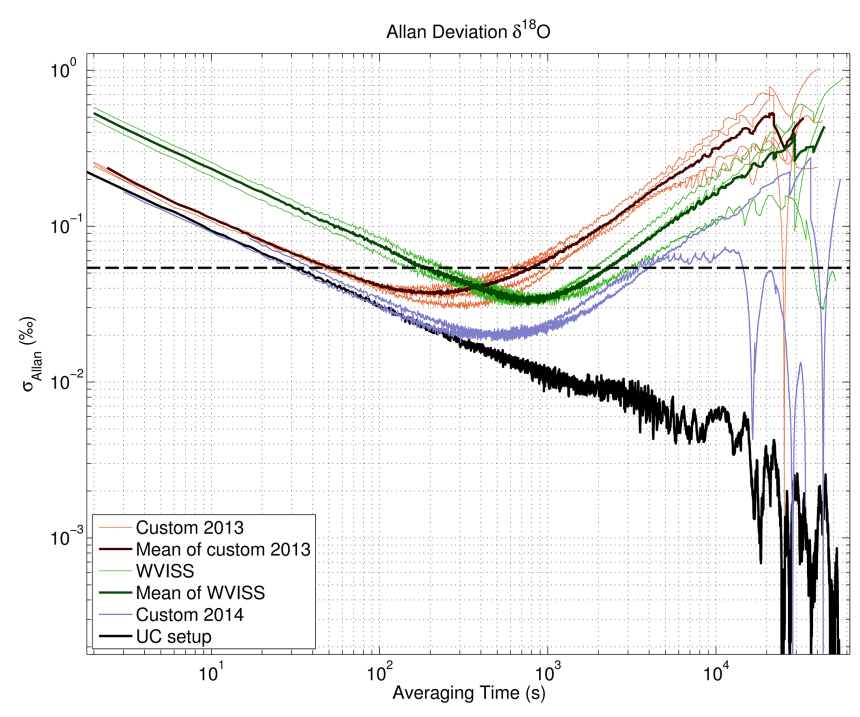

Figure 4. Allan deviation as a function of averaging time for $\delta^{18} \mathrm{O}$ from stability tests of the custom vaporizer setups (2013 setup brown lines and 2014 setup blue lines), the WVISS setup (green line) and the University of Copenhagen setup (UC black line). Average precision ( $1 \sigma$; standard deviation) for individual discrete samples measured on the IWA-35EP analyzer is shown as a black dashed horizontal line.

WVISS setup has $\sigma_{\text {Allan }}$ values of $0.15,0.06$ and $0.10 \%$ for $\delta^{18} \mathrm{O}, \delta \mathrm{D}$ and $\delta^{17} \mathrm{O}$, respectively. For the custom 2013 setup the $\sigma_{\text {Allan }}$ values at $10^{4} \mathrm{~s}$ are and 0.3 and $0.25 \%$ for $\delta^{18} \mathrm{O}$ and $\delta \mathrm{D}$, respectively.

For the custom 2013 setup the precision after integration times of $10^{3} \mathrm{~s}$ are 0.060 and $0.070 \%$ for $\delta^{18} \mathrm{O}$ and $\delta \mathrm{D}$, respectively. For the WVISS setup the precision is $0.035,0.070$ and $0.042 \%$ after $10^{3} \mathrm{~s}$ for $\delta^{18} \mathrm{O}, \delta \mathrm{D}$ and $\delta^{17} \mathrm{O}$, respectively. Preliminary data from the updated custom 2014 setup (blue lines, Figs. 4, 5, and S1) show that this system is less affected by instrumental drift compared to the 2013 setup; after integration times of $10^{3} \mathrm{~s}$ the 2014 system achieves $\sigma_{\text {Allan }}$ values of $0.030 \%$ for $\delta^{18} \mathrm{O}, 0.043 \%$ for $\delta^{17} \mathrm{O}$ and $0.060 \%$ for $\delta \mathrm{D}$.

Results from the University of Copenhagen setup show that the Picarro CRDS analyzer (L2140-i) and vaporizer achieve $\sigma_{\text {Allan }}$ values of $0.011 \%$ for $\delta^{18} \mathrm{O}, 0.010 \%$ for $\delta^{17} \mathrm{O}$ and $0.048 \%$ for $\delta \mathrm{D}$, after averaging times of $10^{3} \mathrm{~s}$. The University of Copenhagen setup achieves higher precision and is less affected by drift compared to the custom and WVISS setups. No instrumental drift can be detected for $\delta^{18} \mathrm{O}$ and $\delta^{17} \mathrm{O}$ for the L2140-i setup (Figs. 4 and S1).

When analyzing for secondary parameters, such as dexcess and ${ }^{17} \mathrm{O}$-excess, a system that is optimized for stability, like the UC setup, has an advantage over the custom and WVISS setups (Fig. S2), which to a larger extent are influenced by instrumental drift (with $\delta^{18} \mathrm{O}$ being more drift sensitive than $\delta \mathrm{D}$ ). The susceptibility of OA-ICOS analyzers to instrumental drift for $\delta^{18} \mathrm{O}$ has also been shown by Aemisegger et al. (2012). Therefore, more frequent measure-

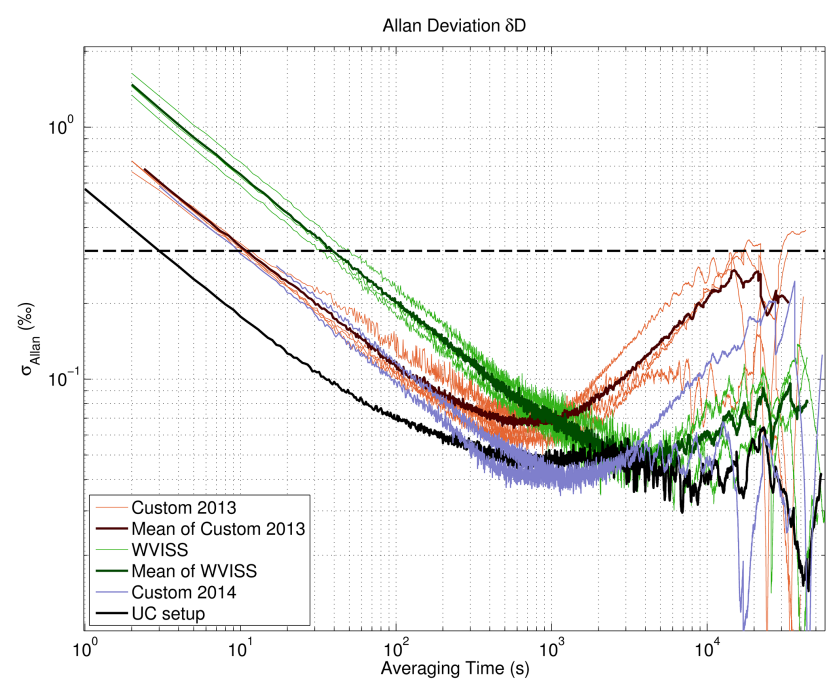

Figure 5. Allan deviation as a function of averaging time for $\delta \mathrm{D}$ from stability tests of the custom vaporizer setups (2013 setup brown lines and 2014 setup blue lines), the WVISS setup (green line) and the University of Copenhagen setup (UC black line). Average precision ( $1 \sigma$; standard deviation) for individual discrete samples measured on the IWA-35EP analyzer is shown as a black dashed horizontal line.

ments of drift correction standards will have to be performed for the custom setups in order to achieve the high precision measurements achieved by the L2140-i setup.

\subsection{Response time}

Isotopic step changes between water standards are used to calculate response times for the customized and the WVISS setup (Tables 4 and 5). The water vapor concentration was kept constant over the isotopic step change ( $20000 \mathrm{ppm})$. Cumulative distribution functions of the log normal distribution were fitted to the isotopic steps following Gkinis et al. (2010).

$\delta_{\text {fit }}(t)=\frac{K_{1}}{2}\left[1+\operatorname{erf}\left(\frac{\ln t-t_{\text {valve }}}{S \sqrt{2}}\right)\right]+K_{2}$,

where $t$ is the time and $K_{1}, K_{2}, t_{\text {valve }}$ and $S$ are constants estimated using least square optimization (LSO). The isotopic transition period, and thus the response time, was defined between 5 and $95 \%$ of the total isotopic step change (Eqs. 4 and 5). Beyond these limits, it becomes difficult to distinguish a step change from random signal noise.

$$
\begin{aligned}
& \Delta \delta_{\text {step }}=\delta_{\text {std1 }}-\delta_{\text {std2 }}, \\
& \delta \%=\frac{\delta_{\text {fit }}-\delta_{\text {std2 }}}{\Delta \delta_{\text {step }}},
\end{aligned}
$$

where $\Delta \delta_{\text {step }}$ is the size of the $\delta$ step between standard 1 $\left(\delta_{\mathrm{std} 1}\right)$ and standard $2\left(\delta_{\mathrm{std} 2}\right)$ and $\delta \%$ is the percent change using the $\delta$ signal from the fitted function in Eq. (3) $\delta_{\text {fit }}$. 
Table 4. Response times for $\delta^{18} \mathrm{O}$ and $\delta \mathrm{D}$ from isotopic step tests between water standards.

\begin{tabular}{|c|c|c|c|c|c|c|c|c|c|c|c|c|}
\hline & & & & & & & & & Respons & time $(\mathrm{s}$ & & \\
\hline Isotopic & tep & Setup & Step & $\Delta^{18} \mathrm{O}$ & $\Delta \mathrm{D}$ & \# steps & $\delta^{18} \mathrm{O}$ & $\pm \sigma$ & Fit mean & & $\pm \sigma$ & Fit mean \\
\hline ITASE & RICE & Custom 2013 & Pos. & 14.5 & 124.2 & 5 & 53.4 & 1.9 & 0.51 & 54.1 & 1.7 & 0.51 \\
\hline RICE & ITASE & Custom 2013 & Neg. & 14.5 & 124.2 & 10 & 54.6 & 1.8 & 0.54 & 55.6 & 0.9 & 1.56 \\
\hline RICE & ITASE & WVISS & Neg. & 14.5 & 124.2 & 7 & 61.3 & 2.6 & 0.55 & 61.8 & 2.4 & 1.82 \\
\hline ITASE & RICE & WVISS & Pos. & 14.5 & 124.2 & 3 & 61.7 & 3.3 & 0.57 & 63.1 & 3.6 & 0.81 \\
\hline RICE & ITASE & Custom 2014 & Neg. & 14.5 & 124.2 & 10 & 18.4 & 0.8 & 0.48 & 18.5 & 1.0 & 1.56 \\
\hline ITASE & WS 1 & Custom 2014 & Pos. & 26.5 & 225.5 & 7 & 18.4 & 0.9 & 0.44 & 18.8 & 0.5 & 0.67 \\
\hline Standard -40 & CPH-DI & Gkinis 2014 & Pos. & 31.6 & 252.6 & 1 & 90.3 & - & 0.33 & 93.6 & - & 1.03 \\
\hline
\end{tabular}

Table 5. Response times for $\delta^{17} \mathrm{O}$ for water standard isotopic step tests.

\begin{tabular}{|c|c|c|c|c|c|c|c|c|}
\hline \multirow{2}{*}{\multicolumn{2}{|c|}{ Isotopic step }} & \multirow{3}{*}{$\begin{array}{l}\text { Setup } \\
\text { WVISS }\end{array}$} & \multirow{3}{*}{$\begin{array}{l}\text { Step } \\
\text { Neg. }\end{array}$} & \multirow{3}{*}{$\begin{array}{r}\Delta^{17} \mathrm{O} \\
(\% 0) \\
7.7\end{array}$} & \multirow{3}{*}{$\begin{array}{r}\text { \# steps } \\
7\end{array}$} & \multicolumn{3}{|c|}{ Response time (s) } \\
\hline & & & & & & \multirow{2}{*}{$\begin{array}{r}\begin{array}{r}\delta^{17} \mathrm{O} \\
\text { mean }\end{array} \\
61.2\end{array}$} & \multirow{2}{*}{$\begin{array}{l} \pm \sigma \\
3.9\end{array}$} & \multirow{2}{*}{$\begin{array}{r}\begin{array}{r}\text { Fit mean } \\
\text { rmse }\end{array} \\
0.79\end{array}$} \\
\hline RICE & ITASE & & & & & & & \\
\hline ITASE & RICE & WVISS & Pos. & 7.7 & 3 & 60.2 & 1.5 & 0.81 \\
\hline RICE & ITASE & Custom 2014 & Neg. & 7.7 & 10 & 19.2 & 1.7 & 0.74 \\
\hline ITASE & WS 1 & Custom 2014 & Pos. & 13.7 & 7 & 19.2 & 2.2 & 0.67 \\
\hline Standard -40 & CPH-DI & Gkinis 2014 & Pos. & 17.0 & 1 & 90.3 & - & 0.34 \\
\hline
\end{tabular}

The response times for the customized setups are $\sim 54$ and $\sim 18$ s for the 2013 and 2014 setup, respectively. This is an improvement compared to the WVISS setup, which has a response time of $\sim 62 \mathrm{~s}$ (Fig. 6, Tables 4 and 5).

The UC L2140-i (Picarro) analyzer and vaporizer unit setup achieves response times of $90 \mathrm{~s}$ for $\delta^{18} \mathrm{O}$ and $\delta^{17} \mathrm{O}$ and $94 \mathrm{~s}$ for $\delta \mathrm{D}$ (Fig. 6e and f, Tables 4 and 5). The custom setups (the 2014 version in particular) are more responsive compared to the WVISS and UC setup.

We hypothesize that a more responsive system can often become less stable when optimized for responsiveness by reducing evaporation chamber volume or increasing the amount of dry air flow. This could partially be due to the fact that it can be harder to control and keep environmental parameters constant in a more responsive system. For example, if the dry air flow is increased to reduce the response time, the system can become more sensitive to ambient temperature changes (as it will be harder to preheat a larger volume of air), which can induce drift. However, another way to obtain a more responsive system would be to minimize the amount of dead volume and mixing volumes in the water sample lines, which would not necessarily result in a less stable system. The dead volume in the sample lines for the custom setups was not minimized due to lab space limitations and due to the fact that the $\delta$-CFA system shared sample lines with other CFA analytical equipment.

Furthermore, the $\delta \mathrm{D}$ isotopic step transition for the WVISS setup (Fig. 6d) is influenced by memory effects. A long tail is evident in the data before the final isotopic value is reached. The fit with the cumulative distribution function (Eq. 3) is poor while an exponential function improves the fit with the data. In contrast, the 2013 and 2014 custom setup reaches the final stable isotopic value faster (Fig. 6b), which suggests it is less influenced by memory effects.

Figure 6 provides an example of a step change between two water standards RICE and ITASE for the custom setups (Fig. 6a and b) and WVISS (Fig. 6c and d) setup. A step change from the UC setup of similar isotopic size is also provided for comparison (Fig. 6e and f). The impulse response functions, the derivative of the isotopic fit $\left(\partial \delta_{\mathrm{fit}} / \partial t\right)$ for the setups, are shown in Fig. $6 \mathrm{~g}$ and $\mathrm{h}$.

The response time values presented in Table 4 are valid as a comparison between the WVISS and custom setups. However, the response times for the custom setups are not representative of the whole CFA system, as the V2 valve is located downstream of the melter and debubbler (Fig. 2). Hence the attenuation of the $\delta$ signal prior to the valve is not taken into account. Gkinis et al. (2011) presented a method to calculate the attenuation for the CFA system using a power spectrum of the CFA data and a spectrum from discrete offline measurements (ice pieces cut directly from the core) over the same depth interval as the CFA measurements.

Aemisegger et al. (2012) reported $\delta \mathrm{D}, \delta^{18} \mathrm{O}$ and water vapor mixing ratio response times of $4.5,3$ and $2.9 \mathrm{~s}$, respectively, for an IWA-WVISS setup. However, their isotopic step change is between one standard from the WVISS unit and the 

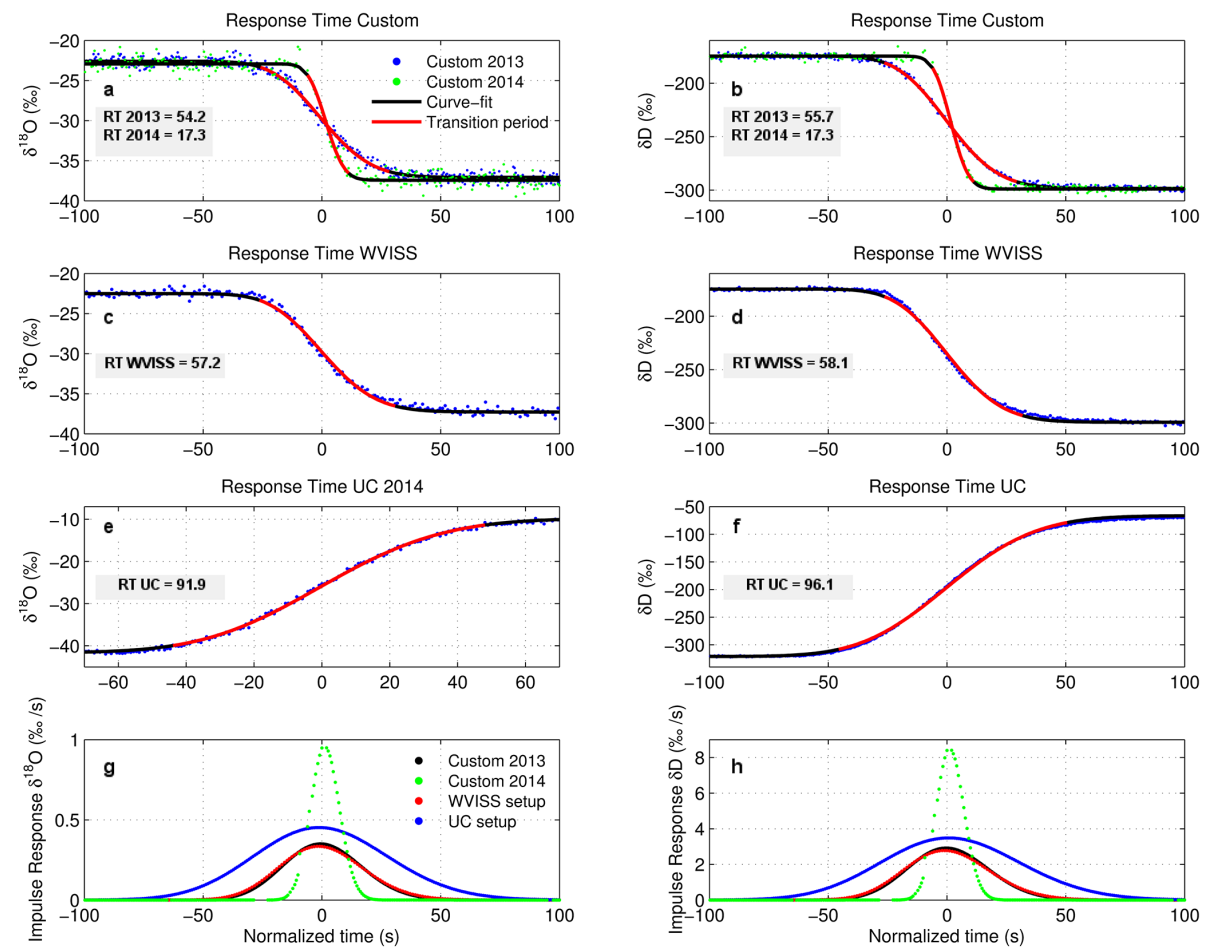

Figure 6. (a-f) Shows $\delta$-CFA data (blue dots and green dots for the 2013 and 2014 custom setup, respectively), a LSO fitted curve (black line), 5 and $95 \%$ of change in the response time (RT) transition period (red line) for the custom setups (a and b) and WVISS setup (c and d) and the University of Copenhagen setup (UC; e and f). (g-h) The impulse response function for the fit for the 2013 custom (black line), the 2014 custom (green line), the Gkinis 2014 (blue line) and the WVISS (red line) setup. The left column of plots (a, c, e and g) are for $\delta^{18} \mathrm{O}$ and the right column of plots $(\mathbf{b}, \mathbf{d}, \mathbf{f}$ and $\mathbf{h})$ are for $\delta \mathrm{D}$.

ambient air, which provides the response times of the IWA. This way the evaporation chamber volume does not have to be replaced for the isotopic step to be complete. When an evaporation unit is used for switching between multiple standards and/or a changing CFA signal (e.g., from CFA sample stream from an ice core), it becomes critical to have a small evaporation chamber volume, as the vapor volume in the evaporation chamber needs to be replaced before the current signal can be analyzed.

The lag bias introduced by the IWA-vaporizer setups are negligible (for both the custom setups and WVISS setups). On average $\delta \mathrm{D}$ lags $\delta^{18} \mathrm{O}$ by $1 \mathrm{~s}$ (Table 4 ). A $\delta$ signal without lag bias enables the calculation of high-frequency d-excess values. For the WVISS and the custom 2014 setup we can also confirm there is no observable bias between $\delta^{18} \mathrm{O}$ and $\delta^{17} \mathrm{O}$, which is relevant for ${ }^{17} \mathrm{O}$-excess measurements (Tables 4 and 5). Furthermore, for the custom setups we find no relationship between the size of the isotopic step and the response time or the response time and the direction of the step (positive or negative).

We reduced the tubing length in our system for the vapor introduction to the analyzer compared to a typical atmospheric science setup, where it is necessary to have longer air intake lines. We hypothesize that our setup experiences less adsorption to tubing walls. This is important, as adsorption can cause a bias between $\delta^{18} \mathrm{O}$ and $\delta \mathrm{D}$. The tubing between evaporation chamber and analyzer is only $59 \mathrm{~cm}$, which required orientating the analyzer with the back towards the WVISS. Moreover, we applied heat tape to the tubing to reduce adsorption to tubing walls.

To conclude discussion on this topic, we note that the response times reported above do not represent the full response time of the entire CFA system, as measured from the melt head. Limited experimentation produced an estimate of $\sim 43$ s for the response time of the entire 2014 CFA system. This is a more rapid response than all systems reported in Table 3 except the custom 2014 setup. Thus, to take full advantage of the fastest response times, the isotope analysis system could be placed closer to the melt head by changing the overall CFA design or shortening the sample line between the melt head and DB1.

\subsection{Calibration}

We use four internal standards (Table 2 and Fig. 7): LHW, Working Standard 1 (WS1), RICE (derived from RICE snow) and ITASE (derived from US-ITASE, West Antarctic snow). The values of the internal standards in relation to the VSMOW/SLAP scale were determined using discrete laser ab- 


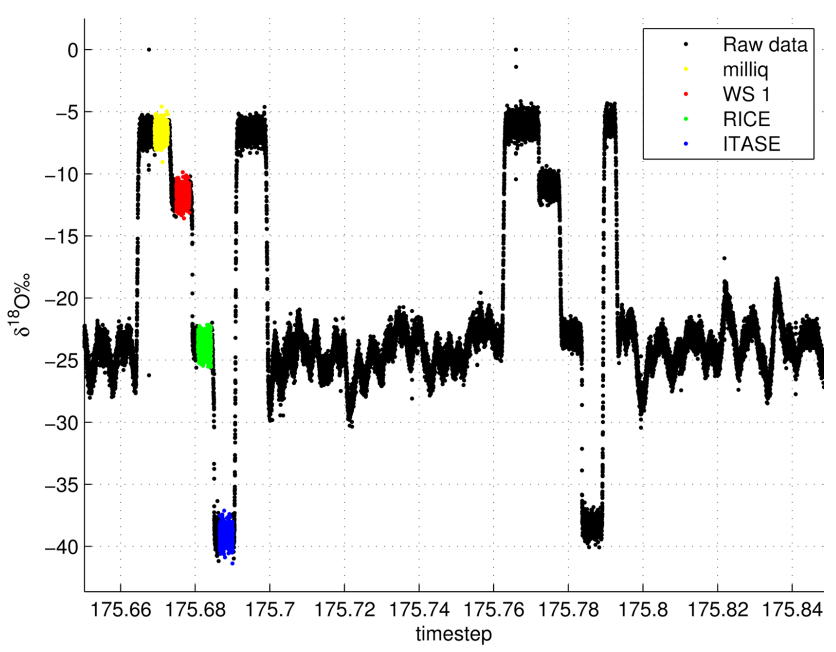

Figure 7. Example of raw data from a melting session and calibration events from 25 June 2013. Ice core sections of $1 \mathrm{~m}$ were stacked on top each other during melting sessions. The ice core data are bracketed by calibration events. Water standards from the first calibration event are color marked. Yellow marking is for LHW standard, red for WS1, green for RICE and blue for the ITASE water standard.

sorption spectroscopy measurements on the IWA-35EP analyzer (Table 2).

The CFA data import and processing is handled with MATLAB routines (MATLAB version 8.0.0.783 (R2012b), MathWorks, Inc., Natick, Massachusetts, United States). A semiautomatic MATLAB script was set up for extracting standard measurements during calibrations and associating calibration events with the corresponding ice core melt section.

Water vapor generated from Milli-Q water (18 $\mathrm{M} \Omega$ water) is supplied to the analyzer between calibration and ice core melting periods, allowing us to easily distinguish between these events. We identify the start of the calibration measurement after the transition from Milli-Q to standard by finding the first time where the derivative of the $\delta$ CFA measurement drops below a threshold. The time lag between the V2 valve and the analyzer is found using the calculated start time of the standard measurement and the time of the valve switch recorded in the calibration log file. Running Milli-Q water when the sample or standards are not analyzed also has the advantage that there is less risk of deposit buildup that can block the nebulizer.

Figure 7 shows an example of a typical section from $\delta$ CFA processing of the RICE ice core. Three or four $1 \mathrm{~m}$ ice core sections were typically melted between calibrations, by stacking consecutive cores on top of each other during melting. Normally the stack of cores takes up to $2.4 \mathrm{~h}$ between calibrations, and one calibration cycle takes $\sim 30 \mathrm{~min}$.

The multiple water standard calibration cycle consists of three internal standards: WS1, RICE and ITASE. The values of the internal standards in relation to the VSMOW/SLAP
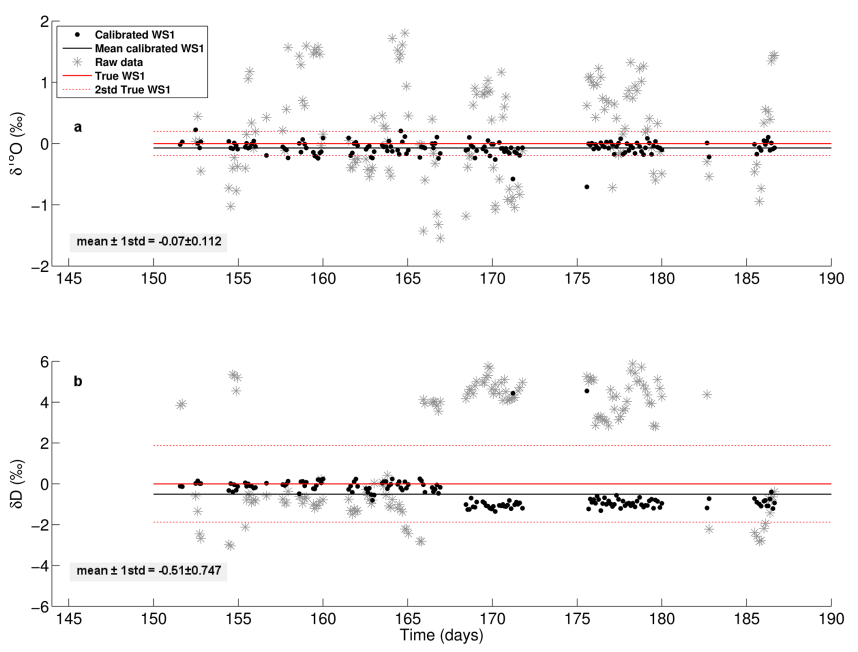

Figure 8. Normalized measurement of QA/QC standard (WS1) over 35 days. Raw data are shown as gray stars and corrected data as black dots (a) for $\delta^{18} \mathrm{O}$ and (b) for $\delta \mathrm{D}$. The corrected data have a standard deviation of 0.11 and $0.75 \%$ for $\delta^{18} \mathrm{O}$ and $\delta \mathrm{D}$, respectively. The mean corrected anomaly (black line) from the true WS1 standard value (thick red line) is -0.07 and $-0.51 \%$ o for $\delta^{18} \mathrm{O}$ and $\delta \mathrm{D}$, respectively.

scale are provided in Table 2. The isotope standards bracket the isotopic ice core record (Fig. 7).

Throughout our measurements the water vapor mixing ratio was kept at $\sim 20000 \mathrm{ppm}$ in order to ensure data stability. To remove data that are affected by sudden changes in water mixing ratios (often caused by small air bubbles or drips) we used the following criteria: CFA data are removed when the difference between the $30 \mathrm{~s}$ moving average and $200 \mathrm{~s}$ moving average of water mixing ratio (ppm) exceeds 1 standard deviation $(\sigma)$ of the $60 \mathrm{~s}$ moving average. In addition, a cutoff limit of $15000 \mathrm{ppm}$ was implemented, which removes data that are stable but measured at mixing ratios that deviate from our set measurement level ( $20000 \mathrm{ppm})$. If an offset occurred from the target water mixing ratio, the analyzer's water vapor dependence is corrected accurately if the magnitude of the offset in between calibrations is constant.

Each standard is analyzed for $500 \mathrm{~s}$; the first 100 and last $100 \mathrm{~s}$ of each standard measurement are discarded to conservatively avoid influence from memory effects. Measurements shorter than $250 \mathrm{~s}$ are omitted. Figure 7 shows an example of the standards analyzed during a calibration cycle. Average values over $300 \mathrm{~s}$ were calculated for each standard.

We follow the recommendation by the International Atomic and Energy Agency (IAEA) of measuring multiple water standards for calibration (Kurita et al., 2012). We fit a multi-port valve to switch between different water standards to the nebulizer to perform calibrations. The RICE and ITASE standards are used for the two-point linear correction of the CFA data. Correction slopes were calculated using the RICE and ITASE standards directly before and directly after 

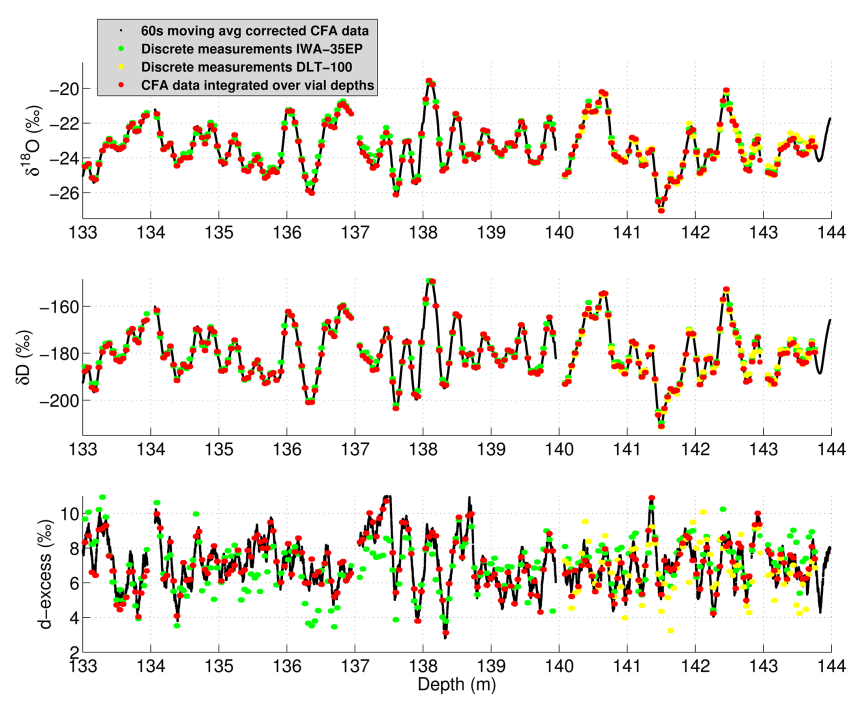

Figure 9. The $60 \mathrm{~s}$ moving average of the corrected $2 \mathrm{~Hz} \delta$ CFA data (black line), results from discrete measurements (green dots for measurements from the IWA-35EP analyzer and yellow dots for measurements on the DLT-100 analyzer) and $\delta$-CFA data integrated over the discrete vial depth intervals (red dots); (a) for $\delta^{18} \mathrm{O}$, (b) for $\delta \mathrm{D}$ and (c) for d-excess.

each melting period. The data are normalized to the RICE standard to reduce the influence from instrument drift and WS1 is used as a QA/QC standard. The calibration and normalization were linearly time weighted between the calibration events.

The averages of correction slopes from calibrations throughout the RICE processing campaign are $\delta^{18} \mathrm{O}=0.941 \pm 0.0057 \quad$ (mean $\pm 1 \sigma ; N=324$ ) and $\delta \mathrm{D}=0.997 \pm 0.0043$. The average of the correction slopes are shown here for characterization purposes. However, for isotope raw-data correction we use adjacent calibration slopes to calibrate the data. This approach was applied as correction slopes have been shown to be instrument specific and vary slightly over time due to instrumental drift (Kurita et al., 2012). To correct for drift, our system is designed for calibrations performed at a time interval averaging $2.4 \mathrm{~h}$. Recent studies have obtained similar correction slopes $\left(\delta^{18} \mathrm{O}=0.941 \pm 0.008\right.$ and $\delta \mathrm{D}=0.994 \pm 0.003$ (Aemisegger et al., 2012) and $\delta^{18} \mathrm{O}=0.946 \pm 0.005$ and $\delta \mathrm{D}=1.00 \pm 0.003$; Kurita et al., 2012) using an IWAWVISS setup. It is important to use a two-point calibration correction, as it is not feasible to calculate correction slopes using a single-standard correction approach, and any resulting deviation from the predominant slope would bias the calibration.

The custom setups can be applied to the field of atmospheric science, enabling rapid, automated and robust calibration cycles using multiple water standards (two-point calibration), compared to the one-standard setup that the unaltered WVISS is fitted with by the manufacturer. Reducing the length of calibration while including multiple standards should maximize data quality while minimizing the loss of atmospheric measurements during calibration cycles. Additionally, the setup has proven to be a robust system that can run continuously for months and operate unattended for days.

\subsection{Long-term precision and accuracy}

The RICE and ITASE standards are used for the two-point linear correction of the $\delta$-CFA data, and the RICE standard is also used for normalization to minimize influence from drift. Measurement of a QA/QC standard (WS1) was conducted as a check throughout the RICE processing campaign (35 days). The corrected CFA measurements of the QA/QC standard provide a measure of the long-term precision and accuracy of the corrected $\delta$-CFA data measured on the custom 2013 setup (Fig. 8). The data in Fig. 8 have been normalized using the VSMOW/SLAP value of the QA/QC standard (WS1; Table 2). The overall precision of the 177 standard measurements over the 35 days was 0.11 and $0.75 \%$ o for $\delta^{18} \mathrm{O}$ and $\delta \mathrm{D}$, respectively. The mean anomaly values of the corrected QA/QC standard values are -0.07 and $-0.51 \%$ o for $\delta^{18} \mathrm{O}$ and $\delta \mathrm{D}$, respectively, and they provide an estimate of the overall accuracy of the measurements (black dashed line in Fig. 8). On 16 June 2013 (day 167), problems were diagnosed with the vacuum pump for the IWA (N940, KNF), which appears to have affected the accuracy of $\delta \mathrm{D}$ (Fig. 8b).

\subsection{High-resolution ice core record}

To evaluate the quality of the calibration procedure, the corrected $\delta$-CFA data were compared to discrete data (Fig. 9). Discrete measurements measured on an IWA-35EP (green dots) and DLT-100 analyzer (yellow dots) can be compared with $\delta$-CFA data integrated over the discrete vial depth intervals (red dots). Figure 9 verifies the validity of the calibration procedure.

The discrete and CFA data for the 133 to $144 \mathrm{~m}$ section of the RICE ice core were investigated further by creating histograms of the difference between the discrete data measured on the IWA-35EP analyzer and the CFA data. A difference was calculated for each discrete sample $(N=215)$. The averages of the CFA $\delta$ over the discrete vial depth intervals were calculated to make a direct comparison with the lower resolution discrete measurements.

The difference between the averaged CFA and discrete data was calculated to be $0.09 \pm 0.16$ and $0.70 \pm 1.07 \%$ o $\left(\right.$ mean $\pm 1 \sigma$ ) for $\delta^{18} \mathrm{O}$ and $\delta \mathrm{D}$, respectively (Fig. 10). dexcess was calculated for the discrete and averaged CFA data, the difference being $-0.05 \pm 0.25 \%$ (Fig. 10c).

\section{Conclusions}

This study outlines the process used to develop experimental CFA equipment for $\delta$ measurements with high temporal 

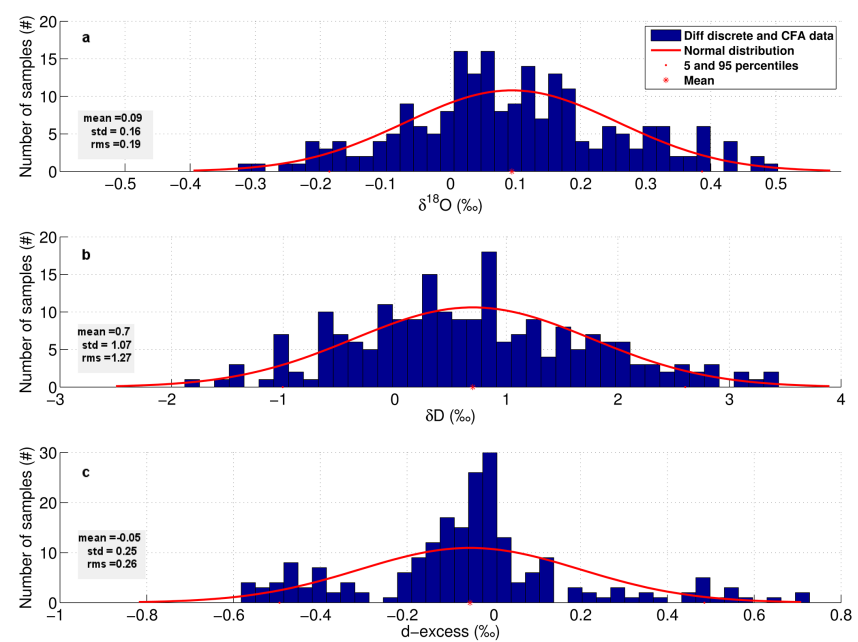

Figure 10. Histogram showing the difference between discrete and the CFA data: (a) for $\delta^{18} \mathrm{O}$, (b) for $\delta \mathrm{D}$ and (c) d-excess for depths from 133 to $144 \mathrm{~m}$ of the RICE ice core.

resolution (sub-annual) in the RICE ice cores and describes the performance and operation of the equipment as well as potential improvements. This continuous-flow laser system is the first to use OA-ICOS in combination with a vaporizer unit to continuously analyze sample from an ice core.

Stability tests comparing the custom and the WVISS setups were performed and Allan deviations $\left(\sigma_{\text {Allan }}\right)$ were calculated to determine precision at different averaging times. For the 2013 modified setup, the $\sigma_{\text {Allan }}$ after integration times of $10^{3} \mathrm{~s}$ are 0.060 and $0.070 \%$ for $\delta^{18} \mathrm{O}$ and $\delta \mathrm{D}$, respectively. The corresponding $\sigma_{\text {Allan }}$ values for the custom 2014 setup are $0.030,0.060$ and $0.043 \%$ or $\delta^{18} \mathrm{O}, \delta \mathrm{D}$ and $\delta^{17} \mathrm{O}$, respectively. For the WVISS setup the precision is $0.035,0.070$ and $0.042 \%$ after $10^{3} \mathrm{~s}$ for $\delta^{18} \mathrm{O}, \delta \mathrm{D}$ and $\delta^{17} \mathrm{O}$, respectively. Both the modified and WVISS setup are influenced by instrumental drift, and $\delta^{18} \mathrm{O}$ is more drift sensitive than $\delta \mathrm{D}$.

The peak precision uncertainty for the custom 2013 CFA $\delta$ data is given by the Allan deviation after $1.2 \mathrm{~h}$ (center point between calibrations), which is $\sim 0.17$ and $\sim 0.13 \%$ o for $\delta^{18} \mathrm{O}$ and $\delta \mathrm{D}$, respectively. Allan deviation for d-excess was estimated to range between 0.31 and $1.37 \%$ using Eq. (2). $1.37 \%$ is the peak uncertainty $(1.2 \mathrm{~h})$ and the minimum uncertainty $(0.31 \%$ o occurs near calibration points, within the optimal integration time for $\delta^{18} \mathrm{O}(200 \mathrm{~s})$.

Results from the UC setup show that the Picarro CRDS analyzer (L2140-i) and vaporizer achieves $\sigma_{\text {Allan }}$ values of $0.011 \%$ of $\delta^{18} \mathrm{O}, 0.010 \%$ of $\delta^{17} \mathrm{O}$ and $0.048 \%$ for $\delta \mathrm{D}$, after averaging times of $10^{3} \mathrm{~s}$. The UC setup outperforms the custom setups on the basis of precision.

The mean response times for the customized setup are 54 and $18 \mathrm{~s}$ for 2013 and 2014 setup, respectively. This is an improvement compared to the WVISS setup, which has a response time of $62 \mathrm{~s}$. The UC L2140-i (Picarro) analyzer and vaporizer unit setup achieves response times of $90 \mathrm{~s}$ for

Acknowledgements. The authors would like to thank two anonymous reviewers for their comments that helped to improve the final version of the paper. We thank Cedric Douence and Andy Phillips for analyzing discrete samples on the DLT-100 LGR analyzer and Valerie Claymore, Bruce Crothers, Ed Hutchinson, Rebecca Pyne and Steve Mawdesley for help with modification of the WVISS. Doug Baer and Manish Gupta (LGR) assisted with optimization discussions and provision of additional equipment. We thank Stefanie Semper for LabVIEW programming.

The funding for the project was provided by the New Zealand Government through GNS Science (Global Change through Time Programme, GNS-540GCT12 and GNS-540GCT32) and Victoria University of Wellington (RDF-VUW-1103).

This work is a contribution to the Roosevelt Island Climate Evolution (RICE) Program, funded by national contributions from New Zealand, Australia, Denmark, Germany, Italy, People's Republic of China, Sweden, United Kingdom and the United States of America. The main logistic support was provided by Antarctica New Zealand (K049) and the US Polar Program (I-209M).

Edited by: R. Koppmann

\section{References}

Aemisegger, F., Sturm, P., Graf, P., Sodemann, H., Pfahl, S., Knohl, A., and Wernli, H.: Measuring variations of $\delta^{18} \mathrm{O}$ and $\delta^{2} \mathrm{H}$ in atmospheric water vapour using two commercial laser-based spectrometers: an instrument characterisation study, Atmos. Meas. Tech., 5, 1491-1511, doi:10.5194/amt-5-1491-2012, 2012.

Allan, D. W.: Statistics of atomic frequency standards, Proc. IEEE, 54, 221-231, 1966.

Baer, D. S., Paul, J. B., Gupta, M., and O'Keefe, A.: Sensitive absorption measurements in the near-infrared region using off-axis integrated cavity output spectroscopy, Appl. Phys. B-Lasers O., 75, 261-265, 2002. 
Berman, E. S. F., Levin, N. E., Landais, A., Li, S., and Owano, T.: Measurement of $\delta^{18} \mathrm{O}, \delta^{17} \mathrm{O}$, and ${ }^{17} \mathrm{O}$-excess in water by offaxis integrated cavity output spectroscopy and isotope ratio mass spectrometry, Anal. Chem., 85, 10392-10398, 2013.

Bigler, M., Svensson, A., Kettner, E., Vallelonga, P., Nielsen, M. E., and Steffensen, J. P.: Optimization of high-resolution continuous flow analysis for transient climate signals in ice cores, Environ. Sci. Technol., 45, 4483-4489, 2011.

Conway, H., Gades, A. M., Hall, B. L., Denton G. H., and Waddington, E. D.: Past and future grounding-line retreat of the West Antarctic Ice Sheet, Science, 286, 280-283, 1999.

Coplen, T. B.: New guidelines for reporting stable hydrogen, carbon, and oxygen isotope-ratio data, Geochim. Cosmochim. Ac., 60, 3359-3360, doi:10.1016/0016-7037(96)00263-3, 1996.

Craig, H., Gordon, L. I., and Horibe, Y.: Isotopic exchange effects on evaporation of water: 1 low-temperature experimental results, J. Geophys. Res., 68, 5079-5087, 1963.

Crosson, E. R.: A cavity ring-down analyzer for measuring atmospheric levels of methane, carbon dioxide and water vapor, Appl. Phys. B-Lasers O., 92, 403-408, 2008.

Dansgaard, W.: Stable isotopes in precipitation, Tellus, 16, 436468, 1964

EPICA Community Members: Eight glacial cycles from an Antarctic ice core, Nature, 429, 623-628, 2004.

Epstein, S. and Mayeda, T.: Variations of ${ }^{18} \mathrm{O}$ content of waters from natural sources, Geochim. Cosmochim. Ac., 4, 213-224, 1953.

Gkinis, V., Popp, T. J., Johnsen, S. J., and Blunier, T. A.: Continuous stream flash evaporator for the calibration of an IR cavity ring-down spectrometer for the isotopic analysis of water, Isot. Environ. Healt. S., 46, 463-475, 2010.

Gkinis, V., Popp, T. J., Blunier, T., Bigler, M., Schüpbach, S., Kettner, E., and Johnsen, S. J.: Water isotopic ratios from a continuously melted ice core sample, Atmos. Meas. Tech., 4, 25312542, doi:10.5194/amt-4-2531-2011, 2011.

Goebel, T. S. and Lascano, R. J.: System for high throughput water extraction from soil material for stable isotope analysis of water, Journal of Analytical Sciences, Methods and Instrumentation, 2, 203-207, 2012.

Gonfiantini, R.: Standards for stable isotope measurements in natural compounds, Nature, 271, 534-536, 1978.

Johnson, L. R., Sharp, Z. D., Galewsky, J., Strong, M., Van Pelt, A. D., Dong, F., and Noone, D.: Hydrogen isotope correction for laser instrument measurement bias at low water vapor concentration using conventional isotope analyses: application to measurements from Mauna Loa Observatory, Hawaii, Rapid Commun. Mass Sp., 25, 608-616, 2011.

Jouzel, J., Alley, R. B., Cuffey, K. M., Dansgaard, W., Grootes, P., Hoffmann, G., Johnsen, S. J., Koster, R. D., Peel, D., Shuman, C. A., Stievenard, M., Stuiver, M., and White, J.: Validity of the temperature reconstruction from water isotopes in ice cores, J. Geoph. Res., 102, 26471-26487, 1997.

Kerstel, E. R. T., van Trigt, R., Dam, N., Reuss, J., and Meijer, H. A. J.: Simultaneous determination of the ${ }^{2} \mathrm{H} /{ }^{1} \mathrm{H},{ }^{17} \mathrm{O} /{ }^{16} \mathrm{O}$ and ${ }^{18} \mathrm{O} /{ }^{16} \mathrm{O}$ isotope abundance ratios in water by means of laser spectrometry, Anal. Chem., 71, 5297-5303, 1999.

Kurita, N., Newman, B. D., Araguas-Araguas, L. J., and Aggarwal, P.: Evaluation of continuous water vapor $\delta \mathrm{D}$ and $\delta^{18} \mathrm{O}$ measurements by off-axis integrated cavity output spectroscopy, At- mos. Meas. Tech., 5, 2069-2080, doi:10.5194/amt-5-2069-2012, 2012.

Küttel, M., Steig, E. J., Ding, Q., Monaghan, A. J., and Battisti, D. S.: Seasonal climate information preserved in West Antarctic ice core water isotopes: relationships to temperature, large-scale circulation, and sea ice, Clim. Dynam., 39, 1841-1857, 2012.

Lee, X., Kim, K., and Smith, R.: Temporal variations of the ${ }^{18} \mathrm{O} /{ }^{16} \mathrm{O}$ signal of the whole-canopy transpiration in a temperate forest, Global Biogeochem. Cy., 21, GB3013, doi:10.1029/2006GB002871, 2007.

Maselli, O. J., Fritzsche, D., Layman, L., McConnell, J. R., and Meyer, H.: Comparison of water isotope-ratio determinations using two cavity ring-down instruments and classical mass spectrometry in continuous ice-core analysis, Isot. Environ. Healt. S., 49, 387-398, 2013.

Masson-Delmotte, V., Hou, S., Ekaykin, A., Jouzel, J., Aristarain, A., Bernardo, R. T., Bromwich, D., Cattani, O., Delmotte, M., Falourd, S., Frezzotti, M., Galle, H., Genoni, L., Isaksson, E., Landais, A., Helsen, M. M., Hoffmann, G., Lopez, J., Morgan, V., Motoyama, H., Noone, D., Oerter, H., Petit, J. R., Royer, A., Uemura, R., Schmidt, G. A., Schlosser, E., Simões, J. C., Steig, E. J., Stenni, B., Stievenard, M., van den Broeke, M. R., van de Wal, R. S. W., van de Berg, W. J., Vimeux, F., and White, J. W. C.: A review of Antarctic surface snow isotopic composition: observations, atmospheric circulation, and isotopic modeling, J Climate, 21, 3359-3387, 2008.

Merlivat, L. and Jouzel, J.: Global climatic interpretation of the deuterium-oxygen 18 relationship for precipitation, J. Geophys. Res., 84, 5029-5033, 1979.

Petit, J.R., Jouzel, J., Raynaud, D., Barkov N.I., Barnola, J.-M., Basile, I., Bender, M., Chappellaz, J., Davis, M., Delaygue, G., Delmotte, M., Kotlyakov, V.M., Legrand, M., Lipenkov, V. Y., Lorius, C., Pépin, L., Ritz, C., Saltzman, E., and Stievenard, M.: Climate and atmospheric history of the past 420000 years from the Vostok ice core, Antarctica, Nature, 399, 429-436, 1999.

Rambo, J., Lai, C.-T., Farlin, J., Schroeder, M., and Bible, K.: Onsite calibration for high precision measurements of water vapor isotope ratios using off-axis cavity-enhanced absorption spectroscopy, J. Atmos. Ocean. Tech., 28, 1448-1457, 2011.

Rhodes, R. H., Bertler, N. A. N., Baker, J. A., Steen-Larsen, H. C., Sneed, S. B., Morgenstern, U., and Johnsen, S. J.: Little Ice Age climate and oceanic conditions of the Ross Sea, Antarctica from a coastal ice core record, Clim. Past, 8, 1223-1238, doi:10.5194/cp-8-1223-2012, 2012.

Schmidt, M., Maseyk, K., Lett, C., Biron, P., Richard, P., Bariac, T., and Seibt, U.: Concentration effects on laser-based $\delta^{18} \mathrm{O}$ and $\delta^{2} \mathrm{H}$ measurements and implications for the calibration of vapour measurements with liquid standards, Rapid Commun. Mass Sp., 24, 3553-3561, doi:10.1002/rcm.4813, 2010

Sinclair, K. E., Bertler, N. A. N., Trompetter, W. J., and Baisden, W. T.: Seasonality of airmass pathways to coastal Antarctica: ramifications for interpreting high-resolution ice core records, J. Climate, 26, 2065-2076, 2013.

Steen-Larsen, H. C., Johnsen, S. J., Masson-Delmotte, V., Stenni, B., Risi, C., Sodemann, H., Balslev-Clausen, D., Blunier, T. Dahl-Jensen, D., Ellehøj, M. D., Falourd, S., Grindsted, A., Gkinis, V., Jouzel, J., Popp, T., Sheldon, S., Simonsen, S. B., Sjolte, J., Steffensen, J. P., Sperlich, P., Sveinbjörnsdóttir, A. E., Vinther, B. M., and White, J. W. C.: Continuous monitor- 
ing of summer surface water vapor isotopic composition above the Greenland Ice Sheet, Atmos. Chem. Phys., 13, 4815-4828, doi:10.5194/acp-13-4815-2013, 2013.

Steig, E. J., Ding, Q., White, J. W. C., Küttel, M., Rupper, S. B., Neumann, T. A., Neff, P. D., Gallant, A. J. E., Mayewski, P. A., Taylor, K. C., Hoffmann, G., Dixon, D. A., Schoenemann, S. W., Markle, B. R., Fudge, T. J., Schneider, D. P., Schauer, A. J., Teel, R. P., Vaughn, B. H., Burgener, L.: Williams, J., and Korotkikh, E.: Recent climate and ice-sheet changes in West Antarctica compared with the past 2000 years, Nat. Geosci., 6, 372-375, 2013.

Steig, E. J., Gkinis, V., Schauer, A. J., Schoenemann, S. W., Samek, K., Hoffnagle, J., Dennis, K. J., and Tan, S. M.: Calibrated high-precision ${ }^{17} \mathrm{O}_{\text {excess }}$ measurements using cavity ringdown spectroscopy with laser-current-tuned cavity resonance, Atmos. Meas. Tech., 7, 2421-2435, doi:10.5194/amt-7-24212014, 2014.
Sturm, P. and Knohl, A.: Water vapor $\delta^{2} \mathrm{H}$ and $\delta^{18} \mathrm{O}$ measurements using off-axis integrated cavity output spectroscopy, Atmos. Meas. Tech., 3, 67-77, doi:10.5194/amt-3-67-2010, 2010.

Thomas, E. R., Bracegirdle, T. J., Turner, J., and Wolff, E. W.: A 308 year record of climate variability in West Antarctica, Geophys. Res. Lett., 40, 5492-5496, 2013.

WAIS Divide Project Members: Onset of deglacial warming in West Antarctica driven by local orbital forcing, Nature, 500, 440-444, 2013.

Werle, P.: Accuracy and precision of laser spectrometers for trace gas sensing in the presence of optical fringes and atmospheric turbulence, Appl. Phys. B-Lasers O., 102, 313-329, 2011. 